\title{
PEMANFAATAN BUKU BERGAMBAR DWI BAHASA UNTUK PENGUASAAN KOSAKATA BAHASA INGGRIS BAGI ANAK-ANAK DI LINGKUNGAN XII KELURAHAN TEGAL SARI
}

\author{
Vidya Dwi Amalia Zati ${ }^{1}$, Lala Jelita Ananda ${ }^{2}$ Anifah $^{3}$, Muhammad Hasyimsyah Batubara ${ }^{4}$ \\ ${ }^{1,2,3}$ Universitas Negeri Medan, Medan, Indonesia, ${ }^{4}$ IAIN Takengon, Aceh, Indonesia \\ vidyazati@unimed.ac.id ${ }^{1,2,3}$, muhammad.hasyimsyahbatubara@gmail.com ${ }^{4}$
}

\begin{abstract}
This community service activity is carried out in Lingkungan XII Kelurahan Tegal Sari Mandala 1. Based on the results of observations and interviews conducted with the community, especially children in Lingkungan XII Kelurahan Tegal Sari Mandala 1, it was found that there were many families from the weak economies who have many children with the low level of English proficiency, both spoken and written. Several factors, such as 1) cause this problem) the low interest in learning, 2) the lack of support for learning English from parents who generally have low education, and 3) the lack of available facilities for learning English, such as learning media and English reading books. The solution offered by the service team in overcoming these problems is to carry out the assistance activity "Utilization of Bilingual Picture Books for Mastery of English Vocabulary for Children in Lingkungan XII Kelurahan Tegal Sari". The stages carried out in this activity are preparing the bilingual pictorial vocabulary books, implementing the assistance activity for children, then followed by an evaluation phase in the form of implementing written tests and interviews for children after participating in the assistance activities. After conducting an evaluation, it can be concluded that this activity positively impacts children in Lingkungan XII Kelurahan Tegal Sari. Based on the written test results, it shows that some children can answer test questions in the form of vocabulary in English well. In addition, through the interview results, it was also obtained many opinions that the children liked the bilingual pictorial vocabulary books used in the assistance activity because the book had exciting pictures and colors.
\end{abstract}

Keywords: Assistance, Vocabulary, Pictorial Book

\begin{abstract}
Abstrak: Kegiatan pengabdian masyarakat ini dilaksanakan di Lingkungan XII Kelurahan Tegal Sari Mandala 1. Berdasarkan hasil observasi dan wawancara yang dilakukan kepada masyarakat terkhusus anakanak di Lingkungan XII Kelurahan Tegal Sari didapatkan informasi bahwa terdapat banyak keluarga dari ekonomi lemah yang mempunyai banyak anak yang memiliki tingkat kecakapan berbahasa Inggris rendah, baik lisan maupun tulisan. Permasalahan ini disebabkan oleh beberapa faktor, seperti 1) rendahnya minat belajar, 2) kurangnya dukungan untuk belajar Bahasa Inggris dari orang tua yang pada umumnya memiliki pendidikan rendah dan 3) kurang tersedianya sarana dalam mempelajari bahasa Inggris, seperti media pembelajaran dan buku-buku bacaan berbahasa Inggris. Solusi yang ditawarkan tim pengabdian dalam mengatasi permasalahan tersebut adalah dengan melaksanakan kegiatan pendampingan "Pemanfaatan Buku Bergambar Dwi Bahasa Untuk Penguasaan Kosakata Bahasa Inggris Bagi Anak-Anak Di Lingkungan XII Kelurahan Tegal Sari”. Adapun tahapan yang dilakukan pada kegiatan pendampingan ini adalah mempersiapkan buku kosakata bergambar dwi bahasa, pelaksanaan kegiatan pendampingan bagi anakanak, lalu dilanjutkan dengan tahap evaluasi berupa pelaksanaan tes tertulis dan wawancara bagi anak-anak setelah mengikuti kegiatan pendampingan. Setelah diadakan evaluasi, dapat ditarik kesimpulan bahwa kegiatan ini berdampak positif bagi anak-anak di Lingkungan XII Keluarahan Tegal Sari, berdasarkan hasil tes tertulis menunjukkan beberapa anak dapat menjawab pertanyaan-pertanyaan tes berupa kosakata dalam bahasa Inggris dengan baik. Selain itu, melalui hasil wawancara juga didapatkan pendapat bahwa anakanak menyukai buku kosakata bergambar Dwi Bahasa yang ditampilkan dalam kegiatan pendampingan, dikarenakan buku tersebut memiliki gambar dan warna yang menarik.
\end{abstract}

Kata Kunci: Pendampingan, Kosakata, Buku Bergambar

\section{Pendahuluan}

Agar dapat mengikuti perkembangan zaman dan teknologi sekarang ini, setiap individu dituntut untuk memiliki kecakapan dalam berbahasa Inggris. Hal ini disebabkan, bahasa Inggris telah 'menginvasi' banyak aspek kehidupan masyarakat, terkhusus aspek 
pendidikan dan teknologi. Bailey \& Gorlach, 1982; 1985; Stevenson, 1994; Crystal, 1997; Graddol, 1997; Komin, 1998 menyimpulkan bahasa Inggris merupakan bahasa dunia dari dulu sampai sekarang. Dengan memiliki kecapakan dalam berbahasa Inggris, maka akan mempermudah setiap orang untuk mengakses pelbagai informasi dan pengetahuan yang kini banyak tersaji secara lengkap di internet yang kebanyakan menggunakan bahasa Inggris. Tuntutan kecakapan dalam berbahasa Inggris ini tidak hanya dianjurkan untuk orang dewasa, tetapi juga untuk anak-anak, dikarenakan dewasa ini ada banyak sumber belajar, informasi dan pengetahuan yang dapat diperoleh dan dipahami dengan mudah apabila anak-anak tersebut memiliki kecakapan dalam berbahasa Inggris. Oleh sebab itu, anak-anak pun mesti memiliki kecakapan dalam berbahasa Inggris agar mampu mengikuti perkembangan zaman. Kemampuan berbahasa Inggris sangat dibutuhkan bila seseorang ingin memiliki kehidupan yang maju (Nishanthi, 2018). Ditambah lagi dengan kenyataan bahwa usia terbaik untuk mempelajari suatu bahasa dimulai dari usia anak-anak, karena usia anak-anak mempunyai kemampuan lebih mudah dalam mengingat, memahami dan mempelajari suatu bahasa, terutama pada periode emas anak, sehingga pembelajaran bahasa Inggris menjadi lebih efektif dilakukan (Oktaviani \& Fauzan, 2017).

Tetapi faktanya di lapangan, kesadaran dalam mempelajari bahasa Inggris ini belum menyentuh semua kalangan masyarakat, kesadaran ini masih terbatas pada anakanak yang berasal dari keluarga dengan ekonomi menengah ke atas, sedangkan anak-anak yang berasal dari keluarga dengan ekonomi lemah masih banyak yang belum memiliki kesadaran tentang pentingnya memiliki kecakapan dalam berbahasa Inggris. Hal ini didapatkan berdasarkan pada hasil observasi yang dilakukan oleh tim pengabdian di Lingkungan XII Kelurahan Tegal Sari Mandala 1 didapatkan informasi bahwa di lingkungan ini terdapat banyak keluarga dari ekonomi lemah yang mempunyai banyak anak yang memiliki tingkat kecakapan berbahasa Inggris rendah, baik lisan maupun tulisan. Permasalahan ini dikarenakan oleh berbagai faktor penyebab, antara lain: rendahnya minat belajar, kurangnya dukungan untuk belajar bahasa Inggris dari orang tua yang pada umumnya memiliki pendidikan rendah serta kurang tersedianya sarana dalam mempelajari bahasa Inggris, seperti media pembelajaran dan buku-buku bacaan berbahasa Inggris.

Sedangkan permasalahan khusus yang dialami anak-anak di Lingkungan XII Kelurahan Tegal Sari perihal yang berkaitan dengan rendahnya kecakapan dalam berbahasa Inggris yakni dikarenakan kebanyakan anak-anak tersebut tidak terampil dalam mengingat kosakata dalam bahasa Inggris. Hal ini sesuai dengan hasil wawancara langsung yang dilakukan kepada beberapa anak di lingkungan tersebut. Berdasarkan pendapat Wiratno \& Santosa (2011) bahasa merupakan alat yang digunakan untuk berkomunikasi yang terorganisasi dalam bentuk kata, kelompok kata, klausa serta kalimat yang diungkapkan secara lisan dan tulisan. Sehingga untuk dapat mempelajari suatu bahasa, dibutuhkan satu keterampilan dalam mengingat kosakata dan maknanya, sebab salah satu unsur penting dari sebuah bahasa adalah kata atau kosakata. Alizadeh (2016) mendefenisikan kosakata sebagai daftar kata yang disusun berdasarkan abjad dan definisi. 
Pendapat lain, Abdullah (2020) menyatakan bahwa kosakata atau kata merupakan simbol yang melambangkan sebuah objek atau ide dalam bentuk rangkaian alfabet.

Kosakata adalah hal mendasar dari sebuah bahasa (Sravani, 2016). Kosakata merupakan inti dan komponen penting dari suatu bahasa, sehingga apabila seseorang memiliki penguasaan yang sedikit tentang kosakata akan mengakibatkan kesulitan dalam berkomunikasi dalam bahasa tersebut (Zimmerman, 1997; Richards \& Renandya, 2002). Bahasa dibuat dari kata-kata, semakin banyak kata-kata yang diketahui, maka akan semakin banyak hal yang dapat diucapkan (Robinson, 2017). Sehingga dapat disimpulkan bahwa kosakata adalah hal terpenting yang harus dipelajari bagi seseorang yang ingin mempelajari suatu bahasa agar dapat berkomunikasi dengan baik dalam bahasa tersebut.

\section{Metode}

Metode yang digunakan sebagai solusi bagi permasalahan ini berupa kegiatan pendampingan kepada kelompok anak-anak usia Sekolah Dasar di Lingkungan XII Kelurahan Tegal Sari Mandala 1. Permasalahan yang menjadi target utama untuk ditangani adalah rendahnya penguasaan kosakata bahasa Inggris anak-anak di lingkungan tersebut, dikarenakan tidak tersedianya media pembelajaran berupa buku-buku bahasa Inggris. Oleh sebab itu, tim Pengabdian Kepada Masyarakat dari Universitas Negeri Medan akan mengadakan kegiatan pendampingan "Pemanfaatan Buku Bergambar Dwi Bahasa Untuk Penguasaan Kosakata Bahasa Inggris Bagi Anak-Anak Di Lingkungan XII Kelurahan Tegal Sari”. Kegiatan ini bertujuan untuk membantu anak-anak di lingkungan tersebut dalam menguasai beberapa kosakata bahasa Inggris. Kegiatan yang dilakukan berupa pembelajaran fun learning dengan menggunakan buku yang memuat kosakata dwi bahasa (Bahasa Inggris \& Bahasa Indonesia), buku tersebut juga disertai gambar dan warna-warni yang menarik secara visual yang tentunya akan disenangi oleh anak-anak. Azizah (2016) mengatakan bahwa dalam penggunaannya biasanya media pembelajaran visual hanya melibatkan indera penglihatan yang terdiri dari berbagai unsur dalam penyajiannya, antara lain garis, rupa, warna dan tekstur. Sehingga saat disajikan akan menarik perhatian para penglihatnya, terutama menarik perhatian, menaikkan minat belajar peserta didik serta dianggap lebih efektif. Seperti yang dinyatakan oleh Akbari (2008) mengenai keefektivitasan pengajaran kosakata melalui gambar dan konteks sudah pernah diuji cobakan pada pelajar di Iran dimana terdapat hasil yang signifikan pada grup anak-anak yang diajarkan kosakata dengan menggunakan gambar dibandingkan dengan anak-anak yang diajarkan dengan konteks. Menurut Annisa (2020) pembelajaran yang menyenangkan akan berdampak positif pada peningkatan kemampuan bahasa Inggris secara natural, serta dapat membantu mengurangi tekanan selama proses pembelajaran.

Selain itu juga diungkapkan oleh Ashari \& Shalehoddin (2018) bahwa minat belajar anak dapat meningkat secara signifikan apabila metode dan pendekatan yang digunakan sesuai. Ditambah lagi dengan penggunaan media pembelajaran yang dapat mempermudah anak-anak dalam memahami isi pembelajaran dan memperjelas tujuan pembelajaran yang ingin disampaikan. Mantei \& Kervin dalam Ratnasari dan Zubaidah (2019) mengatakan bahwasanya buku bergambar adalah salah satu wujud media seni 
Vidya Dwi Amalia Zati, Lala Jelita Ananda, Anifah, Muhammad Hasyimsyah Batubara

visual yang dapat dijangkau oleh anak karena dapat memberikan kesempatan bagi mereka untuk mengeksplorasi pengalaman pribadi dalam menyelami nilai-nilai yang terkandung dalam keluarga maupun sosial. Sehingga pada dasarnya, penggunaan buku bergambar Dwi Bahasa untuk penguasaan kosakata bahasa Inggris pada kegiatan Pengabdian Kepada Masyarakat ini bertujuan untuk menawarkan sebuah solusi dari permasalahan yang dihadapi oleh anak-anak di Lingkungan XII Kelurahan Tegal Sari Mandala 1.

\section{Hasil dan Pembahasan}

Adapun rangkaian kegiatan pelaksanaan pengabdian ini adalah sebagai berikut:

1. Persiapan Buku Kosakata Bergambar Dwi Bahasa

Pada tahap ini, tim pengabdian mempersiapkan buku yang akan digunakan dalam kegiatan pendampingan, berupa buku bergambar dwi Bahasa berisi kosakata dalam Bahasa Inggris dan Bahasa Indonesia dan memuat berbagai gambar dan warna.
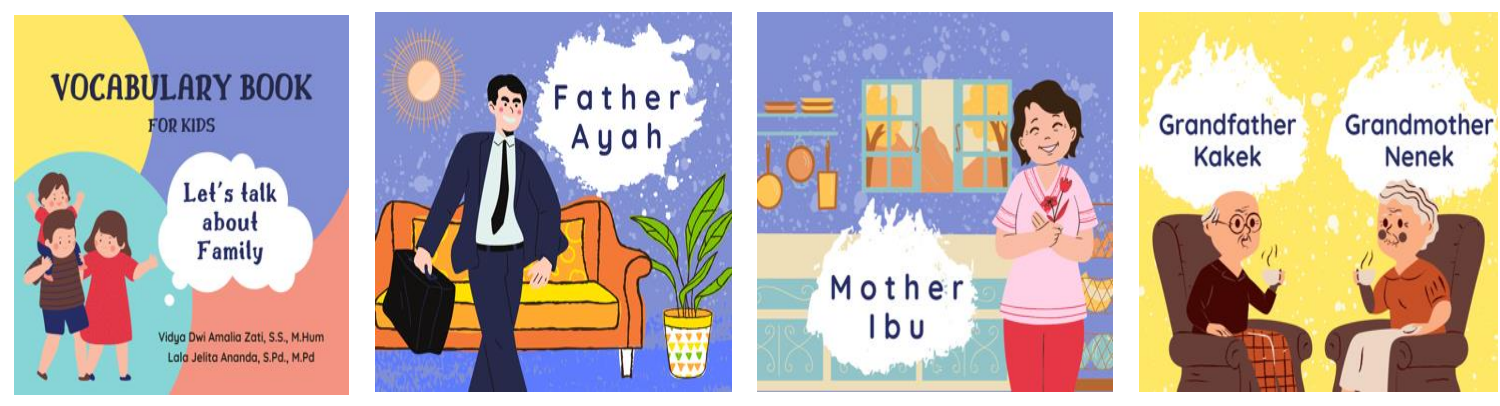

Gambar 1. Buku Kosakata Bergambar Dwi Bahasa

\section{Kegiatan Pendampingan Pemanfaatan Buku Bergambar Dwi Bahasa}

Kegiatan ini dilaksanakan pada tanggal 12 Oktober 2020 di Lingkungan XII Kelurahan Tegal Sari dan dihadiri oleh 13 anak. Pada kesempatan ini dilaksanakan kegiatan pendampingan "Pemanfaatan buku bergambar Dwi Bahasa untuk penguasaan kosakata Bahasa Inggris bagi anak-anak". Materi yang disampaikan berupa kosakata dalam bahasa Inggris dan bahasa Indonesia yang ditampilkan dalam sebuah buku disertai berbagai gambar dan warna-warni yang menarik.

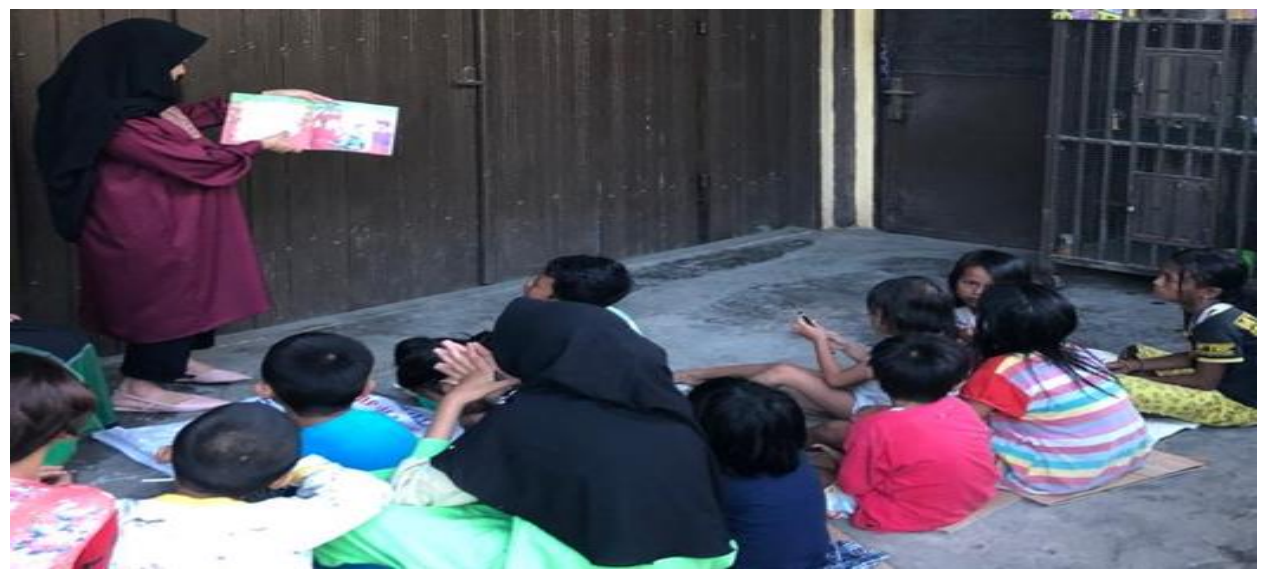

Gambar 2. Kegiatan Pendampingan 


\section{Evaluasi Kegiatan}

Pada tahap ini dilakukan evaluasi terkait pelaksanaan kegiatan yang telah selesai dilakukan. Evaluasi ini dilakukan guna mengetahui penguasaan kosakata bahasa Inggris bagi anak-anak di Lingkungan XII Kelurahan Tegal Sari setelah mengikuti kegiatan pendampingan. Ada 2 kegiatan yang dilaksanakan pada tahap evaluasi ini, yakni:

1. Pelaksanaan Tes Tertulis Setelah Mengikuti Kegiatan

Setelah kegiatan pendampingan "Pemanfaatan Buku Bergambar Dwi Bahasa" selesai dilaksanakan, maka tim pengabdian kepada masyarakat memberikan tes tertulis bagi anak-anak untuk mengetahui penguasaan kosakata bahasa Inggris yang mereka dapatkan setelah mengikuti kegiatan pendampingan. Dalam kegiatan ini, setiap anak diberikan satu tes tertulis berisi beberapa kosakata dalam bahasa Inggris yang harus diartikan ke dalam bahasa Indonesia. Kosakata yang diberikan kepada anak-anak merupakan kosakata yang terdapat di dalam buku cerita bergambar yang digunakan dalam kegiatan pendampingan.

2. Melakukan Wawancara Setelah Mengikuti Kegiatan

Setelah pelaksanaan tes tertulis diberikan kepada anak-anak, tim melakukan wawancara kepada anak-anak di Lingkungan XII Kelurahan Tegal Sari terkait pendapat mereka terhadap buku dwi bahasa yang digunakan dalam kegiatan pendampingan. Hal ini dilakukan sebagai masukan yang bermanfaat untuk memudahkan tim pengabdian dalam merevisi buku bergambar dwi bahasa kosakata bahasa Inggris apabila terdapat kekurangan.

\section{Kesimpulan}

Permasalahan utama yang dihadapi oleh mitra dalam pengabdian masyarakat yang dilakukan di Lingkungan XII Kelurahan Tegal Sari Mandala 1 yakni rendahnya kemampuan penguasaan kosakata bahasa Inggris pada anak-anak, selain itu belum tersedianya bahan-bahan dan buku bacaan bahasa Inggris juga menjadi penunjang terjadinya permasalahan tersebut. Sehingga dengan terlaksananya kegiatan pendampingan ini akan membantu anak-anak dalam penguasaan kosakata bahasa Inggris. Selain itu, tim pengabdian juga memberikan sumbangan buku-buku cerita dwi bahasa yang dapat dimanfaatkan oleh anak-anak di Lingkungan XII Kelurahan Tegal Sari Mandala 1 agar dapat terus mempelajari bahasa Inggris secara mandiri setelah kegiatan pendampingan ini selesai dilaksanakan. Setelah diadakan evaluasi berupa tes tertulis, dapat ditarik kesimpulan bahwa kegiatan ini berdampak positif bagi anak-anak di Lingkungan XII Keluarahan Tegal Sari, berdasarkan hasil tes tertulis menunjukkan beberapa anak dapat menjawab pertanyaan-pertanyaan tes berupa kosakata dalam bahasa Inggris dengan baik. Selain itu, melalui hasil wawancara juga didapatkan pendapat bahwa anak-anak menyukai buku bergambar dwi bahasa kosakata bahasa Inggris yang ditampilkan dalam kegiatan pendampingan, dikarenakan buku tersebut memiliki isi, gambar dan warna yang menarik. 
Vidya Dwi Amalia Zati, Lala Jelita Ananda, Anifah, Muhammad Hasyimsyah Batubara

\section{Ucapan Terima Kasih}

Ucapan terima kasih disampaikan oleh tim pengabdian untuk segenap pihak yang telah membantu dan terlibat dalam pelaksanaan kegiatan pengabdian masyarakat ini, antara lain Universitas Negeri Medan, jurusan Pendidikan Masyarakat FIP Unimed, Kepala Lingkungan serta masyarakat terkhusus anak-anak di Lingkungan XII Kelurahan Tegal Sari.

\section{Daftar Pustaka}

Abdullah, S.C.N., Tulung, G.J., Rambing, R. (2020). Meningkatkan Penguasaan Kosakata Bahasa Inggris Untuk Murid Pendidikan Anak Usia Dini Melalui Buku Cerita Bergambar Pada Kelompok B di TK Suci Castellia. Jurnal Elektronik Fakultas Sastra Universitas Sam Ratulangi, 12(2020). 1-15.

https://ejournal.unsrat.ac.id/index.php/jefs/article/view/27768

Akbari, O. (2008). Teaching Vocabulary Items through Contextualization and Picture to Elementary Iranian EFL Students. Asian EFL Journal, 10(3). 53-77. https://www.asian-efl-journal.com/main-editions-new/teaching-vocabulary-itemsthrough-contextualization-and-picture-to-elementary-iranian-efl-students/

Alizadeh, I. (2016). Vocabulary Teaching Techniques: A Review of Common Practices. International Journal of Research in English Education, 1(1). 22-30. http://ijreeonline.com/article-1-25-en.html

Annisa, N., \& Suwartono, T. (2020). Fun Ways in Learning English. Journal of Applied Linguistics, 2(1). 43-50.

https://www.researchgate.net/publication/343995734_Fun_Ways_in_Learning_Eng lish

Ashari, E., \& Shalehoddin. (2018). Pengenalan Materi Dasar Bahasa Inggris Bagi AnakAnak Usia Dini Di Pulau Mecan, Sekanak Raya, Belakang Padang, Batam. Jurnal Pengabdian Masyarakat Minda Baharu, 2(2). 94-103. https://doi.org/10.33373/jmb.v2i1.1478

Azizah, N. (2016). Pengembangan Media Pembelajaran Buku Bergambar Pada Mata Pelajaran Bahasa Indonesia Materi Menulis Puisi Kelas III Madrasah Ibtidaiyah Darussalamah Tajinan Malang. Undergraduate thesis, Universitas Islam Negeri Maulana Malik Ibrahim.

http://etheses.uin-malang.ac.id/3858/

Boyd, Z. C. (1997). Historical Trends in Second Language Vocabulary Instruction: Second Language Vocabulary Acquisition. Cambridge: Cambridge University Press.

Crystal, D. (1997). English as a Global language. Cambridge: Cambridge University Press.

Graddol, D. (1997). The Future of English. London: The British Council.

Komin, S. (1998). English Language Learning in the 21 st Asian Century. in W.A. Renandya (Ed). Learners and Language Learning. Singapore: SEAMEO RELC.

Nishanthi, R. (2018). The Importance of Learning English in Today World. International Journal of Trend in Scientific Research and Development, 3(1). 871-874. http://dx.doi.org/10.31142/ijtsrd19061

Oktaviani, A., \& Fauzan, A. (2017). Teachers Perceptions about the Importance of English for Young Learners. Linguistic, English Education and Art (LEEA) Journal, 1(1). 1-15. 
https://doi.org/https://doi.org/10.31539/leea.v1i1.25

Ratnasari, E., \& Zubaidah, E. (2019). Pengaruh Penggunaan Buku Cerita Bergambar Terhadap Kemampuan Berbicara Anak. Scholaria: Jurnal Pendidikan Dan Kebudayaan, 9(3). 267-275. https://doi.org/10.24246/j.js.2019.v9.i3.p267-275

Rawlings, A. (2017). How to Speak Any Language Fluently. London: Robinson.

Richard, J., \& Renandya, W. (2002). Methodology in Language Teaching, An Anthology of Current Practice. New York : Cambridge University Press.

Richard W. Bailey \& Manfred, Gorlach. (1982). English as a World Language. Ann Arbor: University of Michigan Press.

Richard W. Bailey \& Manfred, Gorlach. (1985). English as a World Language. Ann Arbor: University of Michigan Press.

Sravani, S. (2016). The Importance of Teaching and Learning English. Research Journal of English Language and Literature (RJELAL), 4(1). 492-494. http://www.rjelal.com/4.1.16\%20B/492-494\%20S.SRAVANI.pdf

Stevenson. R. L. (1994). Global Communication in the 21st Century. New York: Longman

Wiratno, T., \& Santosa, R. (2011). Pengantar Linguistik Umum. Jakarta: Universitas Terbuka. 